\begin{tabular}{|l|l|l||}
\hline \multicolumn{2}{|c|}{ PublisherInfo } \\
\hline \hline PublisherName & $:$ & BioMed Central \\
\hline \hline PublisherLocation & $:$ & London \\
\hline \hline PublisherImprintName & $:$ & BioMed Central \\
\hline \hline
\end{tabular}

\title{
Introns everywhere
}

\begin{tabular}{|l|l|l||}
\hline \multicolumn{2}{|c|}{ ArticleInfo } \\
\hline \hline ArticleID & $:$ & 3675 \\
\hline \hline ArticleDOI & $:$ & $10.1186 /$ gb-spotlight-20000504-01 \\
\hline \hline ArticleCitationID & $:$ & spotlight-20000504-01 \\
\hline \hline ArticleSequenceNumber & $:$ & 112 \\
\hline \hline ArticleCategory & $:$ & Research news \\
\hline \hline ArticleFirstPage & $:$ & 1 \\
\hline \hline ArticleLastPage & $:$ & 2 \\
\hline \hline & & RegistrationDate : 2000-05-04 \\
ArticleHistory & $:$ & OnlineDate $\quad: 2000-05-04$ \\
\hline \hline ArticleCopyright & $:$ & BioMed Central Ltd2000 \\
\hline \hline ArticleGrants & $:$ & \\
\hline \hline ArticleContext & $:$ & 130591111 \\
\hline \hline
\end{tabular}




\section{William Wells}

Email: wells@biotext.com

Self-splicing group II introns can home to the correct place in their host gene by reverse splicing into DNA. In the 27 April Nature, Cousineau et al. show that a bacterial group II intron can also jump into unrelated genes by reverse splicing into an unrelated mRNA, followed by reverse transcription and then recombination (Nature 2000, 404:1018-1021). Moving by reverse splicing ensures that forward splicing will occur at a reasonable frequency, so the host gene's function remains intact. During the period when introns were spreading, cells probably evolved their own splicing machinery both to speed up splicing and to inhibit further intron spreading.

\section{References}

1. Retrohoming of a bacterial group II intron: mobility via complete reverse splicing, independent of homologous DNA recombination.

2. A link to an article on Introns in Nature, [http://www.nature.com/nature/]

This PDF file was created after publication. 